\title{
Population dynamics of the spiny country rat (Niviventer coxingi) in a subtropical montane forest in central Taiwan
}

\author{
Hai-Yin $\mathrm{Wu}^{1 *}$ and Hon-Tsen $\mathrm{Yu}^{2} \dagger$ \\ ${ }^{1}$ Institute of Zoology, Academia Sinica, Taipei, Taiwan, ROC115 \\ ${ }^{2}$ Department of Zoology, National Taiwan University, Taipei, Taiwan, ROC 106 \\ (Accepted 5 May 1999)
}

\begin{abstract}
Population dynamics of the spiny country rat Niviventer coxingi were studied by mark-recapture methods from January 1982 to May 1983 in a subtropical montane forest at Chitou, central Taiwan. The population density was $<8$ rats/ha. The annual pattern of population fluctuation was characterized by summer increase, autumn peak and spring decline. Adult recruits occurred mostly in summer and autumn 1982, whereas young rats joined the population as three cohorts: winter 1981, summer 1982 and winter 1982. Growth patterns differed between winter and summer cohorts, which was attributed mainly to the slow body weight increase in summer cohort males. Males, either adult or juvenile, survived the winter better than females, resulting in the shorter lifespans and the lower number of females in the population. Lifehistory traits in female $N$. coxingi, i.e. short reproductive lifespan, few litters per life time and prolonged maternal care, along with the low breeding intensity, rendered the number of females the limiting factor for population increase. However, females may improve the survival and maturation of their offspring by prolonged maternal care.
\end{abstract}

Key words: Niviventer coxingi, recruitment, survivorship, cohort, life history

\section{INTRODUCTION}

Population dynamics and regulation of population density in small mammals have attracted ecologists' attention for a long time. Extensive efforts have been made to explain the annual cycles in wood mouse Apodemus sylvaticus populations (Watts, 1969; Wilson, Montgomery \& Elwood, 1993), and the multi-annual cycles or the absence of such cycles in microtine populations (Krebs \& Myers, 1974). Emphases of these works have been put on extrinsic factors (such as predators, food, disease) and intrinsic factors (such as social behaviour, territoriality, genetic change). The focus of the intrinsic-factor approach has been shifted from male aggression in the early days to female territoriality, social organization and mating system since the mid-1980s (Watts, 1969; Ostfeld, 1985; Montgomery, 1989a, $b$; Montgomery et al., 1991). Recently, based on three behavioural phenomena (female territoriality, dispersal and reproductive suppression), Wolff (1997) presented a conceptual model for population regulation in mammals.

\footnotetext{
* Present address: Institute of Natural Resources Management, National Dong Hwa University, Shou-Feng, Hualien, ROC 974 $\uparrow$ All correspondence to: H.-T. Yu, Department of Zoology, National Taiwan University, Taipei, Taiwan, ROC 106
}

Most hypotheses and models of population regulation in small mammals have been developed from knowledge of several well-studied species. Studies on other species, especially species outside Euro-American continents, are needed to test the validity of the existing models and hypotheses.

The genus Niviventer is a group of 15 species once classified under the genus Rattus and elevated to its present generic level by Musser (1981). All but one species of the genus are found in the Oriental (or Indomalayan) region (Corbet \& Hill, 1992). Niviventer species are known to be forest-dwelling rodents (Nowak, 1991). Recent surveys in China show that four species, $N$. andersoni, $N$. confucianus, $N$. fulvescens and $N$. niviventer, are dominant in forest ecosystems. They can sometimes be found in wasteland, and yet are never known to thrive in cultivated areas such as tea plantations, croplands and grass lands (Bao \& Zhung, 1987; Hong, 1987; Wu \& Deng, 1988; Zhang, 1993; Bao et al., 1995; Wu, Luo \& Fox, 1996).

Two Niviventer species occur in Taiwan, $N$. culturatus and $N$. coxingi. Both are endemic to the island and are parapatric to each other in elevational distribution ( $\mathrm{Yu}$, 1994). These two species are primarily forest-dwellers. Niviventer culturatus is found in montane forests from 1500 to $3700 \mathrm{~m}$ above sea level and prefers micro- 
habitats associated with large fallen logs (Adler, 1996). Niviventer coxingi is distributed from sea level to $1500 \mathrm{~m}$ and previous trapping records show that its presence in any habitat is often difficult to predict. When it does exist in a habitat, such as lowland secondary forests, the population density is usually low and there is no other syntopic terrestrial rodents (Yu, 1994).

The population dynamics of $N$. coxingi have only been studied in two areas, one in Yangmingshan National Park by Chang-Chien (1989) and Chang (1991) and the other in Chitou, central Taiwan (this study). The field work in Chitou was conducted by H.-T. Yu 15 years ago. However, only post-natal growth of a litter has been described (Lin \& Yu, 1987) and the annual reproductive cycle has been recently reported, based on histological examination ( $\mathrm{Yu} \& \mathrm{Lin}$, 1999). Little is still known about the population dynamics of this endemic rodent species.

We describe the population dynamics of $N$. coxing $i$ inhabiting a forested slope to characterize demographic attributes and life-history traits of the species.

\section{MATERIALS AND METHODS}

The study was conducted at an experimental forest station of National Taiwan University, Chitou, central Taiwan $\left(23^{\circ} 40^{\prime} \mathrm{N}, 120^{\circ} 47^{\prime} \mathrm{E}\right.$; elevation $\left.1100-1400 \mathrm{~m}\right)$ for 17 months, from Januray 1982 to May 1983. The climate in Chitou is cool and humid. Average monthly temperature ranges from 11 to $22{ }^{\circ} \mathrm{C}$. Annual precipitation is $3000 \mathrm{~mm}$, with a rainy season extending from March to September. Relative humidity is about $90 \%$ year-round. Most of the vegetation in Chitou is a combination of coniferous and bamboo plantations. The original broadleaf forest occurs only along a steep slope where the study was conducted.

The trapping grid covered $c .9$ ha; about half of the grid was situated in a natural forest and half in a 20 year-old Japanese fir Cryptomeria japonica plantation. A total of 220 mesh-wire rodent traps $(24 \times 15 \times 11 \mathrm{~cm})$ were set at $20-\mathrm{m}$ intervals whenever possible depending on the topography (Fig. 1). Two traps (1 on the ground and 1 on a tree trunk $c .1 .5 \mathrm{~m}$ high) were set at every trapping station in the coniferous plantation and 1 trap (on the ground) per station in the natural forest. Traps on tree trunks were set by another study for monitoring tree squirrels in the coniferous plantation. Traps were baited with sweet potatoes for 5 nights in the first 2 months (January-February 1982), 4 nights from March 1982 to February 1983 and 3 nights in the last 3 months (March-May 1983). Trapped individuals were marked with numbered ear tags, and body weight, body length and tail length were measured. The reproductive condition was examined: for males, position of testes and length of scrotum were recorded; for females, vaginal perforation, pregnancy and lactation were noted. According to its body weight, each rat was assigned as young $(<110 \mathrm{~g})$ or adult $(\geq 110 \mathrm{~g})$. Yu \& Lin (1999) studied the age determination in $N$. coxingi. They

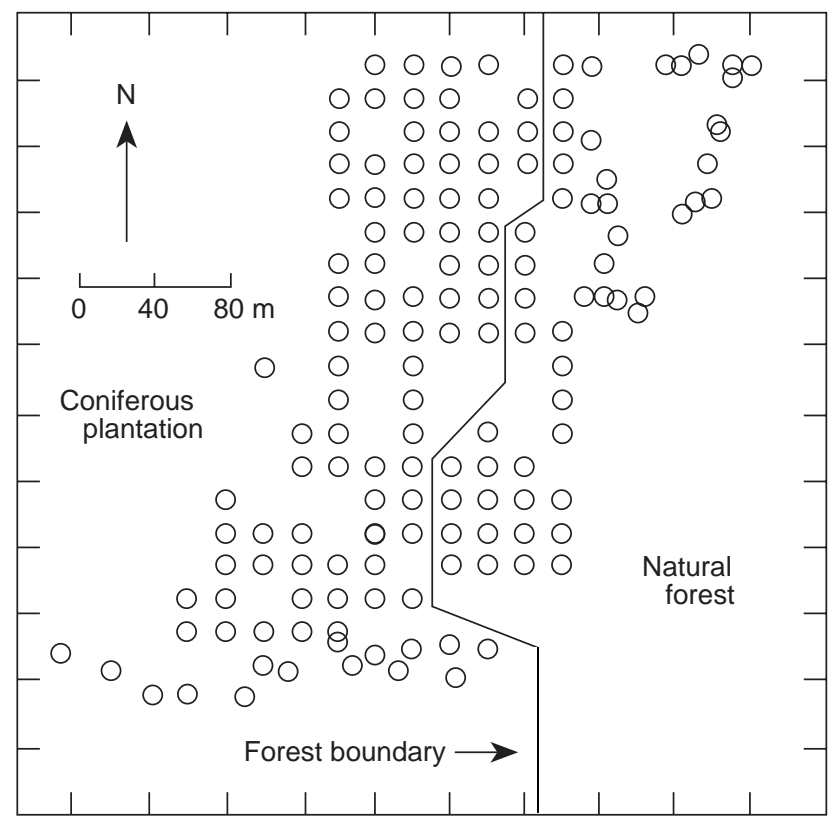

Fig. 1. The layout of trapping sites (open circles) in the study area at Chitou, central Taiwan.

defined 5 age classes by tooth-wear patterns. The $110 \mathrm{~g}$ we chose here is the cut-off point of body weight between $\mathrm{Yu} \&$ Lin's age classes II and III. Consequently, our young and adults are equivalent to their age classes I-II and III-V, respectively (Yu \& Lin, 1999). Capture rates, defined as numbers of captures per 100 trap-nights (TN), were calculated over the whole study, for each month, and for either sex.

Rats that were captured for 3 months or longer were assumed to be residents, and those that were captured for $<3$ months were treated as transients. Since residents might be classified as transients if the trappability was low, the minimum unweighted trappability averaged over individuals (Sullivan \& Sullivan, 1980; Krebs \& Boonstra, 1984) was calculated to access the risk of misclassification. The disappearance of either transients or residents may have been a result of mortality or emigration. However, it was not possible in the present study to distinguish between the 2 causes. Moreover, it was difficult to determine whether new individuals were natively born or were moving in from surrounding areas. Therefore, we assumed that rats first caught as young were born within the grid and those as large adults (> $>40 \mathrm{~g}$ in body weight) at their first captures were immigrants. Two points substantiate the above assumption; 30 of the 97 rats that have been captured as adults were first marked as young, and 30 of the 63 rats that were first marked as young grew into adults in the study area. No attempt was made to distinguish young adults (body weights $110-140 \mathrm{~g}$ ) as immigrants or native born. Newly marked rats were referred to as recruits of the month or of the season.

Ages and seasons of birth were estimated for young rats from their body weights of first captures with reference to the postnatal growth pattern (Lin \& Yu, 1987). Each young was then assigned as winter cohort 
(born in autumn) or summer cohort (born in spring) of the year.

Growth pattern of body weight was examined in winter- and summer-cohort young of either sex. Eight males ( 5 of winter cohort and 3 of summer cohort) and 7 females ( 4 of winter cohort and 3 of summer cohort) that were young at their first captures and had continuous body-weight records for 4-14 months were selected for the analysis. Means of the monthly body weight increments of these rats from their first captures to $>130$ $\mathrm{g}$ were calculated by the growth formula, $\ln \left(W_{i+1} / W_{i}\right)$, where $W_{i}$ is the body weight of the individual in month $i$ (Simpson, Roe \& Lewontin, 1960).

To analyse seasonal variation, we defined 6 seasons by combining monthly data: (1) winter 1981, JanuaryFebruary 1982; (2) spring 1982, March-May 1982; (3) summer 1982, June-August 1982; (4) autumn 1982, September-November 1982; (5) winter 1982, December 1982-February 1983; (6) spring 1983, March-May 1983.

\section{RESULTS}

\section{Capture rates and trappability}

A total of $146 N$. coxingi were trapped 828 times in 14520 trap-nights. The overall capture rate was 5.7 per $100 \mathrm{TN}$ and the monthly capture rates ranged from 2.3 to 10.1 per $100 \mathrm{TN}$. Minimum unweighted trappability was $77.4 \%$ for males and $76.9 \%$ for females. The high trappability reduced the likelihood of mistaking transients for residents.

Niviventer coxingi has a slight tendency to climb in trees. Of the 473 captures in the two-trap stations, $11.3 \%$ of the captures were above ground level. The capture rates in these two-trap stations were 1.1 per 100 $\mathrm{TN}$ for traps above ground level and 8.5 per $100 \mathrm{TN}$ for traps on the ground.

\section{Population size and sex ratio}

Seasonal population size, estimated as minimum number known alive (MNA), ranged from 26 to 59, or 3-7 individuals/ha (Fig. 2). MNA was low in spring and peaked in autumn. The total numbers of rats that were marked were 84 males and 62 females. There were more males than females in all the seasons except summer 1982, but the bias was not significant $\left(\chi^{2}=3.86\right.$, d.f. $=5$, $P>0.05$ ) (Fig. 2). Rapid increase in the MNA for females was observed in summer 1982, for males it was in autumn 1982. However, the actual time lag between the two sexes was only 1 month.

\section{Recruitment}

To examine further the causes of the population increase, we plotted the numbers of seasonal recruits by

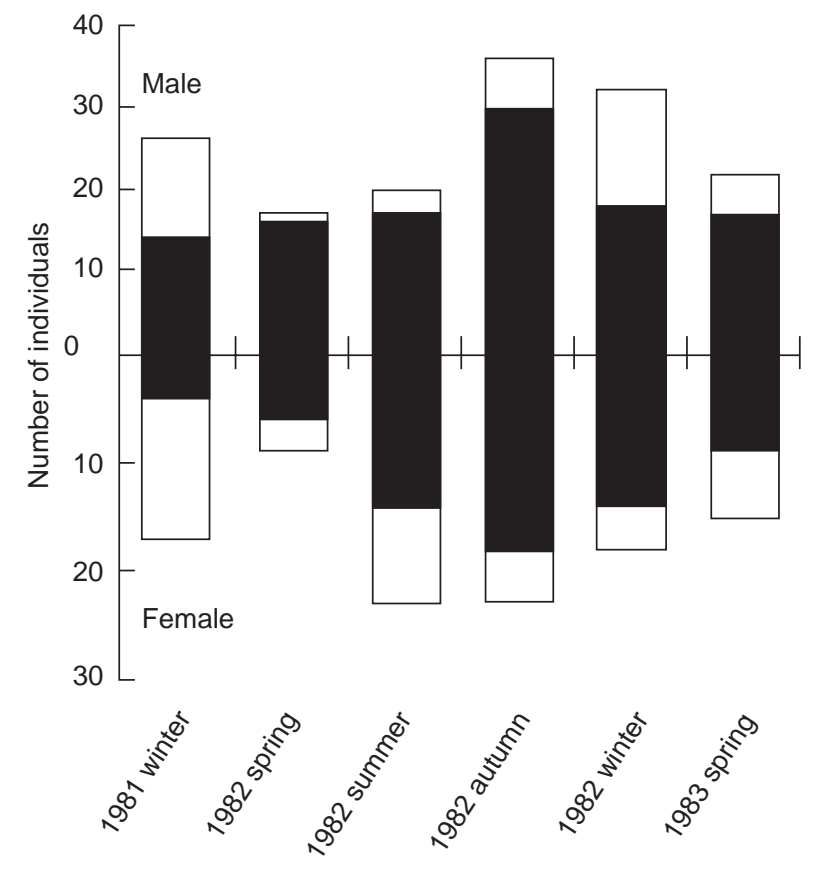

Fig. 2. Seasonal variation in the MNA of males and females by age groups. Adults, closed bars; young, open bars. Rats weighing $<110 \mathrm{~g}$ at the first captures in each season were classified as young.

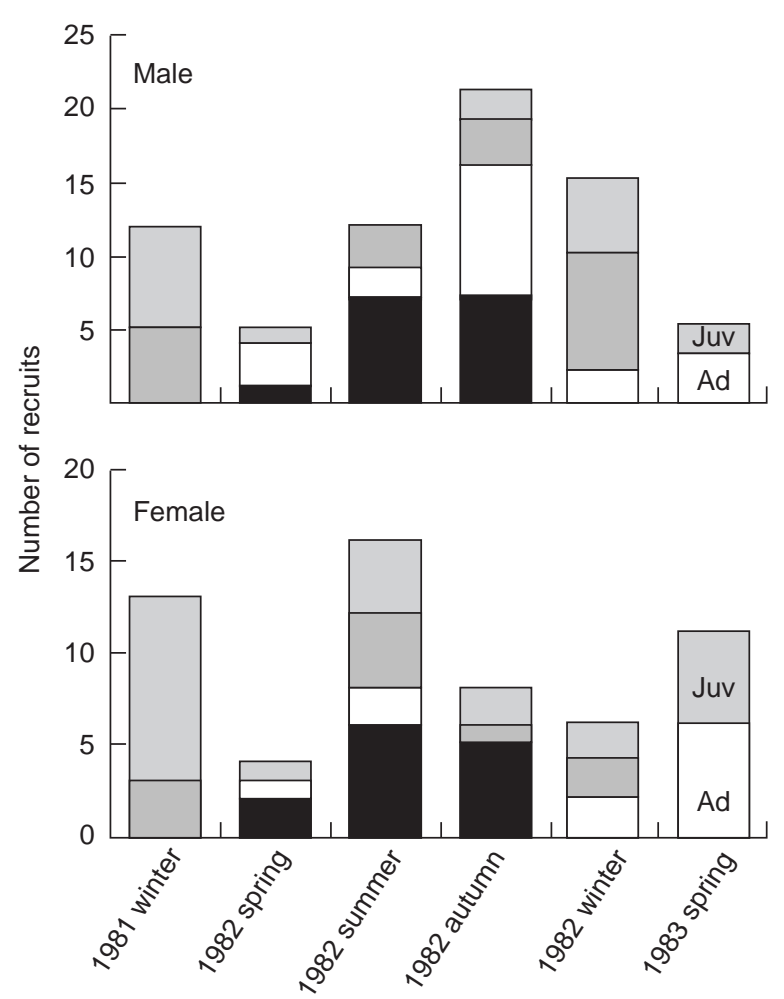

Fig. 3. Seasonal variation in the number of adult or young recruits that stayed as residents or were captured for $<3$ months, i.e. transients. $\square$, young transients; $\square$, young residents; $\square$, adult transients; and $\square$, adult residents. Only young recruits were shown in spring 1981; recruits in spring 1983 were classified only as adults (Ad) or young (Juv). 
their age and residency (Fig. 3). When both adults and young were considered, the number of recruits peaked one season later in males (autumn 1982) than in females (summer 1982), as in the MNA analysis. The high recruitment of males in autumn 1982 was due primarily to adult immigrants (16 out of 21 recruits). For females, the recruits in summer 1982 were composed of equal numbers of adults and young.

Three events can be inferred from Fig. 3. First, young recruitment was found mainly in three seasons, winter 1981, summer and winter 1982. Second, the major seasons of adult recruitment for both sexes were in summer and autumn 1982. More large males (>200 g) and more large females $(>150 \mathrm{~g})$ joined the population in summer 1982 than in autumn 1982 (WilcoxonMann-Whitney test, $P>0.05)$. The residential tendency for adult recruits in summer and autumn was higher in females $(85 \%)$ than in males $(56 \%)$. However, the sexual difference was not significant (Fisher's exact test, $P>0.05)$. Third, the probability of becoming resident was age-dependent. The residential tendencies for the adults and young recruiting into the population from spring through winter 1982 were $48 \%$ and $64 \%$ in males, and $72 \%$ and $44 \%$ in females. However, none of the differences reach the $5 \%$ significant level by $\chi^{2}$ test.

\section{Survivorship and body weight increment of the cohorts}

Three cohorts could be distinguished: winter 1981 cohort, summer 1982 and winter 1982 cohorts. The three cohorts have different sex ratios: while winter 1981 cohort consisted of equal sexes (male : female $=12: 13$ ), the other two cohorts had biased sex ratios, summer 1982 cohort in favour of females (male: female $=5: 11$ ) whereas winter 1982 cohort in favour of males (male : female $=16: 5$ ).

The probability of the three cohorts surviving until spring 1983 was significantly higher in males than in females $\left(36 \%\right.$ vs $\left.7 \% ; \chi^{2}=7.51, P<0.01\right)$. It could be explained by the cohort- and sexual-differences in survivorship. Figure 4 depicts the survivorship curves of the three cohorts in either sex. All curves except one (males of the summer 1982 cohort) drop precipitously during the first season; roughly $50 \%$ or more young disappeared. Three of the five males of the summer 1982 cohort were still alive in spring 1983. On the contrary, all the 11 females of the same cohort disappeared in spring 1983. Winter cohort males did better than concohort females in surviving the first winter they encountered: when the two winter cohorts were combined, $46 \%$ males and $28 \%$ females could be trapped in spring. Yet the sexual difference was not significant $\left(\chi^{2}=0.91\right.$, d.f. $=1, P>0.05$ ).

We describe growth patterns by monitoring body weights of young males and females in either cohort through time (Fig. 5). The patterns are different by cohort. Means of the monthly increments for individual rats differed significantly between cohorts (two-way ANOVA, $\left.F_{1,11}=13.35, P<0.005\right)$, and yet there was no
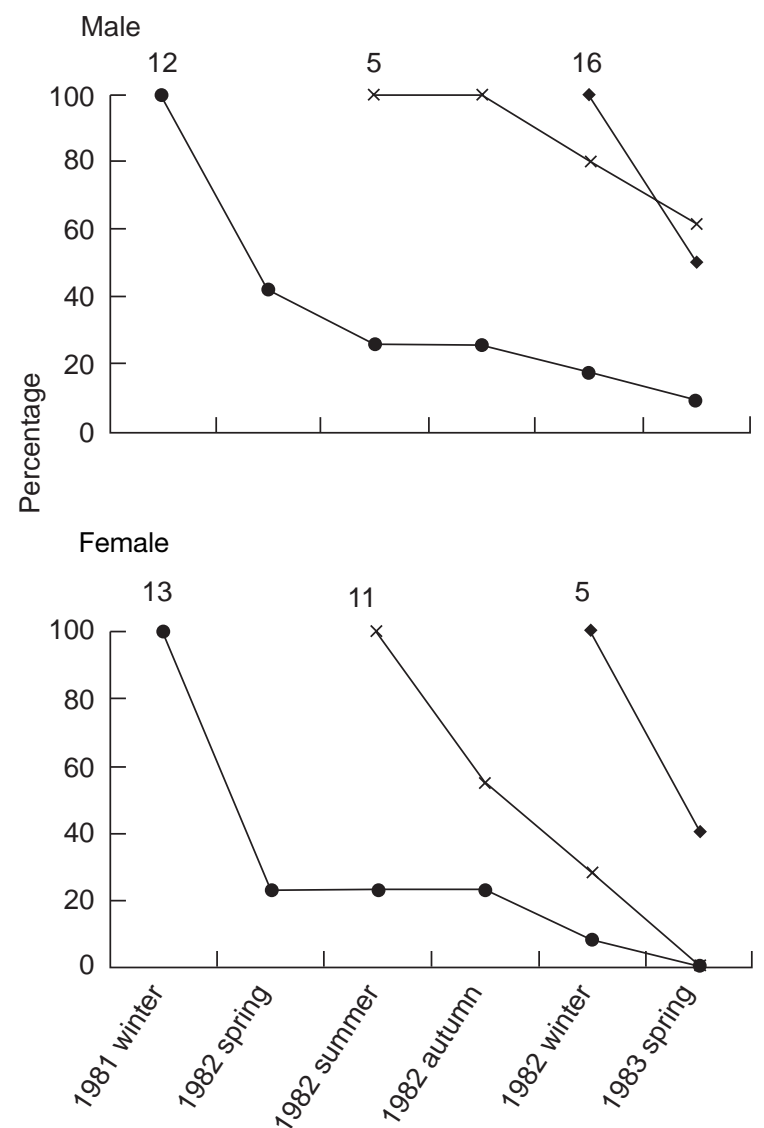

Fig. 4. Survivorship curves of winter 1981, summer 1982 and winter 1982 cohorts, showing the percentages of rats in each cohort that were still captured in the following seasons. Numbers on top of the figure indicate the numbers of rats in each cohort.

relevant difference between sexes $\left(F_{1,11}=1.67, P>0.05\right)$. The significant difference between cohorts was attributed mainly to the slow body weight increase in males of summer cohort. The body weights of winter cohort males increased from $50-80 \mathrm{~g}$ to $150 \mathrm{~g}$ within 3-4 months (Fig. 5). However, the body weights of summer cohort males were stable at about $80-130 \mathrm{~g}$ for $4-6$ months during autumn and winter, and therefore increased rapidly to more than $150 \mathrm{~g}$ within 1 or 2 months in spring (Fig. 5).

\section{Disappearance schedule of adults}

The disappearance schedule of adult recruits is shown in Fig. 6. Similar to in young cohorts, the percentage of adult males surviving the winter was higher than that of adult females although the difference is not significant (46\% vs 31\%; Fisher's exact test, $P>0.05$ ). However, the probabilities for all the adult recruits to survive until spring 1983 were similar in both sexes $(11 \%$ vs $9 \%)$.

The body weight distribution of the recruiting adults were examined to deduce the dispersal schedule of the rats. Body weights of recruiting adults at first capture 


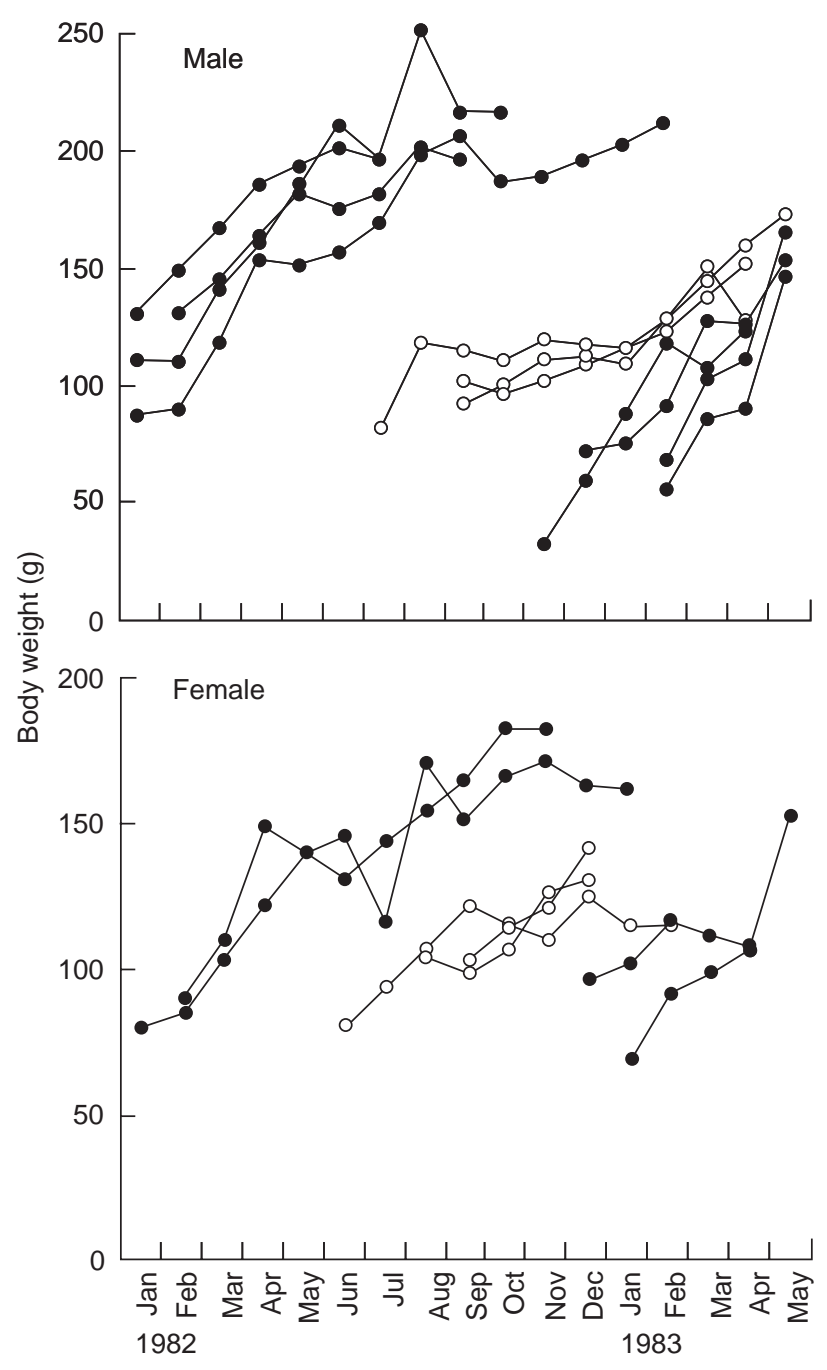

Fig. 5. Growth pattern in body weight of rats of the winter cohort (O) and the summer cohort $(\bigcirc)$.

ranged from 110 to $250 \mathrm{~g}$ for males and from 110 to $200 \mathrm{~g}$ for females. The body weight distributions of recruiting adults differed between sexes. The percentages of recruiting adults weighing over $170 \mathrm{~g}$ (equivalent to age class $\mathrm{V}$ by $\mathrm{Yu} \&$ Lin, 1999) was higher in males than in females $\left(36 \% v\right.$ s $12 \% ; \chi^{2}=3.94$, d.f. $=1, P<0.05$ ). This observation indicates that males would even disperse long after attaining adulthood.

\section{DISCUSSION}

\section{Two cohorts a year}

The occurrence of young indicates that $N$. coxingi produces two cohorts a year, a summer cohort born in spring and a winter cohort born in autumn. The pattern is similar to that found in a population of N. coxingi in northern Taiwan (Chang, 1991). However, Yu \& Lin (1999) have examined the specimens of $N$. coxingi collected from nearby areas of the present study and conclude that the species can
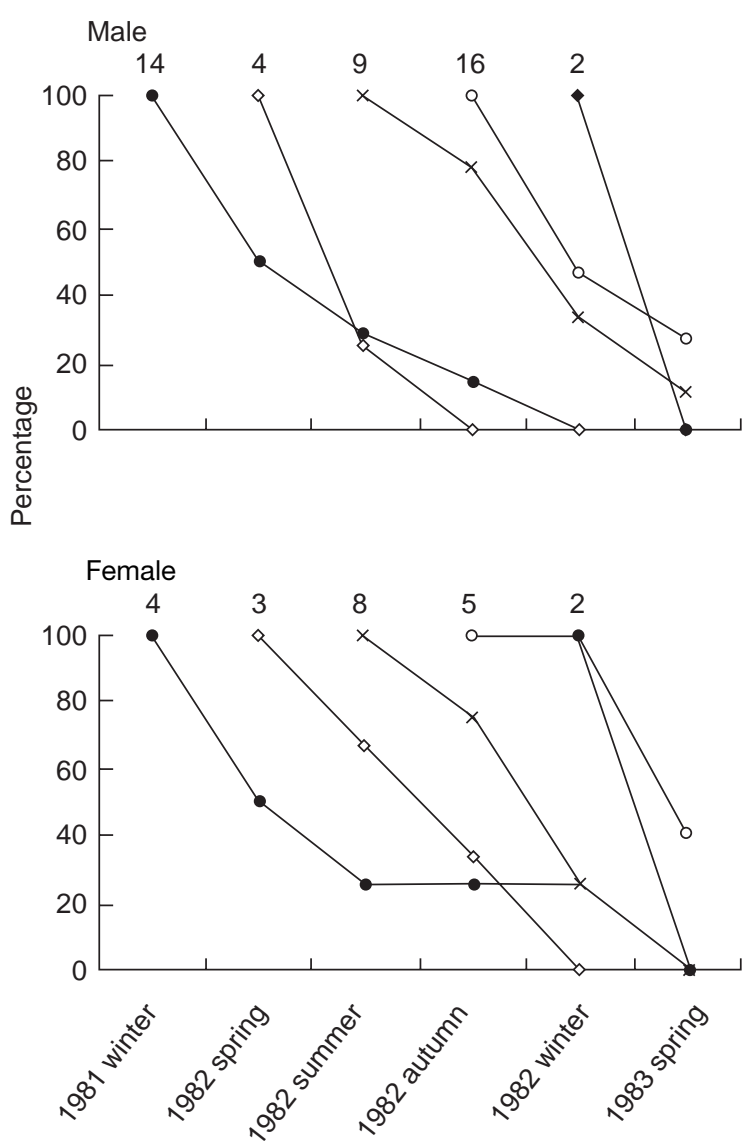

Fig. 6. Disappearance schedule of the adult recruits in each season, showing the percentages of adult recruits in each season that were still captured in the following seasons. Numbers on top of the figure indicate the numbers of recruits in the each season.

breed year-round, but breeding activities of the females seem to be suppressed in winter, perhaps by low temperature and a shortage of food supply. The seemingly discrepant results may be a result of differences in field methods. Chang (1991) and this study monitored the populations by live-trapping, while Yu \& Lin (1999) removed rats from the population for autopsy and histological examination. If breeding by females is suppressed by social factors or limiting resources as suggested by Ims (1987), continuous removal of individuals may eliminate such suppression effects, resulting in the breeding pattern observed by Yu \& Lin (1999). Furthermore, by chance alone or by using marginal resources, some rats in the population were likely to breed out of season. Therefore, $N$. coxingi could breed year-round but with two major breeding seasons in a year.

\section{Cohort and sexual differences in life-history traits}

In $N$. coxingi, some life-history traits, such as growth rate, age at maturity and longevity, differ with cohorts and sexes. 


\section{Growth rate and age at maturity}

The analysis of growth in body weight indicates that the winter cohort grew faster than the summer cohort. Similar patterns have been reported elsewhere. Leirs et al. (1990) and Delany \& Monro (1985) noticed the reduced growth rates in Mastomys and Arvicanthis at the end of the dry season and associated the patterns with rainfall, probably through rainfall-induced variation in quality and quantity of food resources.

The rapid growth rates for winter cohort males enables them to reach sexual maturity soon in spring. These males could grow to over $150 \mathrm{~g}$ by spring or summer. However, for males of the summer cohort, the body weights lingered around 110-130 g and their testes did not descend into scrota during the entire winter. In male $N$. coxingi, only about $50 \%$ at age III (c. 110 $130 \mathrm{~g}$ in body weight) were sexually matured, while $>80 \%$ at age IV (c. $140-180 \mathrm{~g}$ ) were producing sperm (Yu \& Lin, 1999). Thus, at least half of the males from the summer cohort could not begin to breed until the next spring.

Growth and maturation patterns in the females present a different scenario. Females of the winter and summer cohorts would grow to over $110 \mathrm{~g}$ in spring and late summer, respectively. For females weighing over $110 \mathrm{~g}, 80 \%$ were sexually mature ( $\mathrm{Yu} \& \mathrm{Lin}, 1999)$. Consequently, females of the winter cohort would be sexually mature the next spring while those of the summer cohort start to breed by the end of the year they were born. In other words, summer cohort females may channel energy into reproduction instead of growth at an earlier age than males.

\section{Longevity}

The lifespan of $N$. coxingi is sex- and cohort-dependent. Inferring from the disappearance schedule of adults and the growth pattern of juveniles, we found that males had longer life spans than females, and individuals of the winter cohort lived longer than those of the summer cohort. Males of the winter cohort could persist in the population for six seasons or longer (Fig. 4). Males of the summer cohort might survive five to six seasons, one season shorter than the winter cohort. For females, the longevity was about five seasons in winter cohort, but was only three to four seasons in summer cohort.

\section{Demography and life-history traits}

Some demographic attributes of this $N$. coxingi population, such as sex ratios and the patterns of recruitment and residency, are related to the life-history traits of the winter and summer cohorts.

The moderately male-biased sex ratio in the population can be explained by the sexual difference in longevity and survivorship. Males, either adult or juvenile, did better than females in surviving the winter.
Moreover, lifespans of males were one to three seasons longer than those of females. Thus, there should be more cohorts of males that females simultaneously present in each season. For example, in summer, three cohorts of males (adults of the two cohorts from the previous year and young of the summer cohort of the present year) were present in the population. However, there were only two cohorts of females (winter cohort of the previous year and the present summer cohort) present at the same time.

Although breeding activity began in spring, the major breeding season in the study area was in late summer and autumn when the number of adult rats in the population peaks. Most females recruiting into the population in summer and autumn stayed as residents. However, recruiting males in autumn tended to be transients. The pattern could be explained by temporal variation in the 'attractiveness' of the study area to adult males. Wilson et al. (1993) found in the wood mice Apodemus sylvaticus that it was the number of females available for copulation rather than the absolute number of females that determines the attractiveness of an area to males. In Chitou, the increasing number of adult females in summer would attract adult males. However, the availability of receptive females soon decreased because, in this population, females were fewer than males and, in autumn, most of the females should be preoccupied by maternal care, which is prolonged in $N$. coxingi. With limited number of available mates, adult males were prone to disperse. The broad range in body weights of recruiting males also suggests that immigration and emigration are frequent in males and they may disperse once or twice after attaining adulthood. However, only a few females would disperse after having reached sexual maturity.

\section{Females as a limiting factor for population increase}

In $N$. coxingi, few females could survive the winter to the second spring during their lifespans, which implies that the breeding lifespans of most females are $<1$ year. To maximize its fitness, a female with such a short breeding lifespan should try to produce as many litters as possible by evolving life-history traits such as accelerated juvenile growth and shortened maternal care. However, the performance of $N$. coxingi in these lifehistory traits is on the other side of the continuum: juvenile growth is delayed and maternal care is prolonged.

Growth is a slow process for juvenile $N$. coxingi. It takes 2 months for juveniles to reach $30 \mathrm{~g}$ (or $21.4 \%$ of adult body weight; Yu \& Lin, 1999). In Rattus lutreolus, the body weight of a 2-month-old juvenile is already $50 \%$ of that of adults (Fox, 1979). Compared with some Rattus species, it also takes longer for $N$. coxingi to become sexually mature (Lin \& Yu, 1987). The evidence for prolonged maternal care for $>2$ months comes from two field observations of simultaneous captures of a mother and its 2-month-old offspring in a cage 
(Lin \& Yu, 1987). Prolonged maternal care would limit the litter number a female can produce during its lifetime. $\mathrm{Yu} \&$ Lin (1999) find all of the 50 parous female $N$. coxing $i$ had only one or two sets of placental scars, indicating that most females produce two litters at most.

Moreover, the intensity of breeding activity is low in adult females. During this study, only $13 \%$ of 62 females were found pregnant or lactating. Low breeding intensity of female $N$. coxing $i$ was also reported by others: e.g. $26 \%$ females have ever been recorded as in reproductive condition in a 19-month study (Chang, 1991); $36 \%$ of the female specimens examined by $\mathrm{Yu} \& \mathrm{Lin}$ (1999) were pregnant or lactating. Breeding intensity in females is likely to be density- or resource-dependent (Wilson, et al., 1993; Adler \& Beatty, 1997). However, in $N$. coxingi, it is not likely to be density-dependent becasue the population density is usually low.

Recent studies on rodents suggest an important role of females in population regulation by a density-dependent effect in female reproductive activity (Montgomery, 1989a; Wilson et al., 1993). Spatial and social interactions between females may be involved in the process of population regulation (Getz, Dluzen \& McDermott, 1983; Lambin \& Krebs, 1991). In this study, we find that the features of female $N$. coxingi make it a limiting factor in population growth. The number of females, particularly the number of females surviving the winter, would determine the size of the summer cohort, which in turn influences the number of recruiting males and the population size at peak. However, under low population density, the number of female $N$. coxingi would only determine the population size in autumn, instead of regulating population abundance in a density-dependent way. There might be habitat- or resource-related extrinsic factors responsible for checking population increase (Wilson et al., 1993; Wolff, 1997).

The fitness of female $N$. coxingi is limited by its short reproductive lifespan, low breeding intensity, delayed juvenile development and prolonged maternal care. However, the reproductive success of females can still be ensured, if not maximized, by the enhanced offspring survival under prolonged maternal care. It is yet to be determined whether these features are shared by related species or are specific to $N$. coxingi in a resource-limited habitat. Comparative study of the life-history traits and population dynamics of the allopatric $N$. culturatus would shed light on these questions.

\section{Acknowledgements}

C. L. Luo and S. P. Yo assisted in the field work without reservation. This study was supported by the National Science Council (NSC), Republic of China. During the preparation of the manuscript, HTY was supported by a NSC grant (88-2311-B-002-051) and HYW by a grant from Institute of Zoology, Academia Sinica. Two anonymous reviewers offered comments and help to improve the manuscript. We thank them all.

\section{REFERENCES}

Adler, G. H. (1996). Habitat relations of two endemic species of highland forest rodents in Taiwan. Zool. Stud. 35: 105-110.

Adler, G. H. \& Beatty, R. P. (1997). Changing reproductive rates in a Neotropical forest rodent, Proechimys semispinosus. J. Anim. Ecol. 66: 472-480.

Bao, Y., Ding, P., Zhung, Y. \& Hu, Y. (1995). Studies on the composition and dynamic of small mammal community in the East Zhoushan Island. Acta Theriol. Sin. 15: 222-228 (in Chinese)

Bao, Y. \& Zhung, Y. (1987). Ecological study of rodents in Jinhua Beishan Mountain. Acta Theriol. Sin. 7: 266-274 (in Chinese)

Chang, S. W. (1991). The population ecology of Niviventer coxingi in the Miantienshan area. Master's thesis, National Taiwan University (in Chinese).

Chang-Chien, L. W. (1989). The ecology of rodents in the Miantienshan area of Yangmingshan National Park. Master's thesis, National Taiwan University (in Chinese).

Corbet, G. B. \& Hill, J. E. (1992). The mammals of the Indomalayan region. Natural History Museum Publications. New York: Oxford University Press.

Delany, M. J. \& Monro, R. H. (1985). Growth and development of wild and captive Nile rats, Arvicanthis niloticus (Rodentia: Muridae). Afr. J. Ecol. 23: 121-131.

Fox, B. J. (1979). Growth and development of Rattus lutreolus (Rodentia: Muridae) in the laboratory. Aust. J. Zool. 27: 945-957.

Getz, L. L., Dluzen, D. \& McDermott, J. L. (1983). Suppression of reproductive maturation in male-stimulated virgin female Microtus by a female urinary chemosignal. Behav. Proc. 8: 59-64.

Hong, C. (1987). On the space disposition and structure of rodent communities in East Fujian mountainous area. Acta Theriol. Sin. 7: 203-210.

Ims, R. A. (1987). Male spacing systems in microtine rodents. Am. Nat. 130: 475-484.

Krebs, C. J. \& Boonstra, R. (1984). Trappability estimates for mark-recapture data. Can. J. Zool. 62: 2440-2444.

Krebs, C. J. \& Myers, J. H. (1974). Population cycles in small mammals. Adv. Ecol. Res. 8: 267-399.

Lambin, X. \& Krebs, C. J. (1991). Spatial organization and mating system of Microtus townsendii. Behav. Ecol. Sociobiol. 28: $353-363$.

Leirs, H., Stuyck, J., Verhagen, R. \& Verheyen, W. (1990). Seasonal variation in growth of Mastomys natalensis (Rodentia: Muridae) in Morogoro, Tanzania. Afr. J. Ecol. 28: 298-306.

Lin, Y. S. \& Yu, H. T. (1987). Postnatal growth and development of the spiny rat, Niviventer coxingi (Swinhoe, 1864). Bull. Inst. Zool. Acad. Sin. 26: 1-7.

Montgomery, W. I. (1989a). Population regulation in the wood mouse, Apodemus sylvaticus. I. Density dependence in the annual cycle of abundance. J. Anim. Ecol. 58: 465-475.

Montgomery, W. I. (1989b). Population regulation in the wood mouse, Apodemus sylvaticus. II. Density dependence in spatial distribution and reproduction. J. Anim. Ecol. 58: 477-494.

Montgomery, W. I., Wilson, L., Hamilton, R. \& Mccartney, P. (1991). Dispersion in the wood mouse, Apodemus sylvaticus: variable resources in time and space. J. Anim. Ecol. 60: 179-192.

Musser, G. G. (1981). Results of the Archbold expeditions No. 105. Notes on systematics of Indo Malayan murid rodents and descriptions of new genera and species from Ceylon, Sulawesi, and the Philippines. Bull. Am. Mus. Nat. Hist. 168: 229-334.

Nowak, R. M. (1991). Walker's mammals of the World. 5th edn. Baltimore: The Johns Hopkins University Press.

Ostfeld, R. S. (1985). Limiting resources and territoriality in microtine rodents. Am. Nat. 126: 1-15. 
Simpson, G. G., Roe, A. \& Lewontin, R. C. (1960). Quantitative zoology. New York: Harcourt, Brace \& Co.

Sullivan, D. S. \& Sullivan, T. P. (1980). Deer mouse trappability in relation to bait preference. Can. J. Zool. 58: 2282-2284.

Watts, C. H. S. (1969). The regulation of woodmouse (Apodemus sylvaticus) numbers in Wytham Woods, Berkshire. J. Anim. Ecol. 38: 285-304.

Wilson, W. L., Montgomery, W. I. \& Elwood, R. W. (1993). Population regulation in the wood mouse, Apodemus sylvaticus (L.). Mammal. Rev. 23: 73-92.

Wolff, J. O. (1997). Population regulation in mammals: an evolutionary perspective. J. Anim. Ecol. 66: 1-13.

Wu, D. \& Deng, X. (1988). The community structure of myomorpha rodents in the tropical and subtropical mountainous forests in Yunnan Province, (China): I. species diversity, relative abundance, density and biomass. Acta Theriol. Sin. 8: $25-32$.

Wu, D. L., Luo, J. \& Fox, B. J. (1996). A comparison of ground dwelling small mammal communities in primary and secondary tropical rainforests in China. J. Trop. Ecol. 12: 215-230.

Yu, H. T. (1994). Distribution and abundance of small mammals along a subtropical elevational gradient in central Taiwan. J. Zool. (Lond.) 234: 577-600.

Yu, H. T. \& Lin, Y. S. (1999). Age, reproduction and demography of the spiny rat (Niviventer coxingi; Muridae) in subtropical montane forests of central Taiwan. Zool. Stud. 38: 153-163.

Zhang, J. (1993). Studies on the population ecology of sulphur bellied rat. Acta. Theriol. Sin. 13: 198-204. 